\title{
Making space for expressive and creative writing in African primary Schools: a two-site action research study in Kenya and South Africa ${ }^{1}$
}

\author{
PAULA GAINS Molteno Institute for Language and Literacy (MILL, South \\ Africa) \\ BARBARA GRAHAM Summer Institute of Linguistics / Bible Translation and \\ Literacy ( Kenya)2
}

\begin{abstract}
Similar concerns about the development of children's creative writing abilities in Kenya and South Africa prompted two Mother Tongue (MT) education practitioners in Summer Institute of Linguistics (SIL) and Molteno Institute for Language and Literacy of Linguistics (MILL) to undertake parallel intervention studies to increase teachers' competence in writing pedagogy and improve the quantity and quality of learners' writing. Most early literacy teachers have had no experience themselves of expressive writing, so it is not surprising that this activity rarely, if ever, features in public school early literacy classrooms. The hypothesis which formed the basis for this action research study was that educators, exposed to extensive and expressive writing themselves, will be more skilled in the generation of such activities with learners. This paper reports on the workshop processes in the two sites, identifying similarities and differences in the experience. Whilst the hypothesis, though tested, remains unproven, this paper presents findings that are of relevance to further study in the area of writing pedagogy research and also to teachers and teacher educators involved in writing in the primary school.
\end{abstract}

Education action research - a systematic enquiry conducted by practitioners with a vested interest in the teaching and learning process - is most often carried out by teachers who want to better understand and improve an aspect of their work. This paper describes action research which involved teachers, but

\footnotetext{
${ }_{1}$ An earlier version of this article was presented as a conference paper and was submitted for inclusion in the conference proceedings of the Multilingualism Conference July 2010, to be published by Kenyatta University.

${ }^{2}$ The authors acknowledge the valuable input made to this article by Mandisa Magwaza of the Molteno Institute for Language and Literacy (MILL, South Africa).
}

READING AND WRITING 
originated with practitioners working at the level of programme facilitation. However, the paper is as much about exploring the possibility of collaboration and synergy between two similarly focused non-governmental education organisations, as it is about the action research project that jointly ensued.

Summer Institute of Linguistics (SIL) and Molteno Institute for Languages and Literacy (MILL) have had fleeting contact over a number of years in relation to projects and potential projects in Ghana and Sudan; both of these non-profit organisations have a central and strong belief in the importance of using mother tongue as the medium for early literacy and of thereby promoting marginalised African languages. Whereas the possibility existed for 'turf wars' between the two organisations on the promotion of different approaches to mother tongue pedagogy, there was a recognition on the part of both organisations that the issue is bigger than the reach, or potential reach, of any single organisation and must be focused rather on important educational, cultural and, we believe, moral principles. In relation to such important values, both organisations recognise the importance of collaboration rather than competition. Thus, the Director of Academic Affairs for SIL Africa Area proposed that Barbara Graham, a mother tongue specialist based in Kenya, visit South Africa in October 2009 to have an exchange of information about the different approaches and explore with MILL the possibilities for collaboration.

Clearly there are differences in the approaches of the two organisations. Briefly stated, SIL works with local communities, where invited, assisting them to build capacity for language related development projects which include Bible translation, adult literacy and children's education involving mother tongues. SIL uses a number of teaching strategies in its literacy and mother tongue education provision. MILL has developed an early literacy methodology for Grades One, Two and Three called Breakthrough to Literacy (also referred to below as Breakthrough). This methodology is a version of the approach developed in the United Kingdom in the 1960s by the linguist Michael Halliday. It recognises and builds on learners' oral and aural competencies in their mother tongue, and is "founded on an understanding and interpretation of what language is and what part it plays in our lives" (Halliday, 1978: 205). Using learners' own ideas and utterances as a basis for the production of written texts, Breakthrough "starts from what learners know, i.e. their spoken language, and uses this to help them learn something new, i.e. how to read and write" (Molteno Project, 2004: 1). Breakthrough works even more effectively in African languages than in English because of the regular phoneme/grapheme relationships in the spelling and pronunciation. MILL implements Breakthrough in Africa by working with teams made up of early grade teachers together with curriculum and language specialists, to develop versions of the course that suit the language and the learners' context. Teachers are then trained in the 
methodology and receive classroom support for their implementation work. So far, Breakthrough has been translated into fifty African languages and is being used in nine sub-Saharan countries.

One outcome of the meeting between MILL and SIL was the realisation that in both countries, teachers, in their efforts to facilitate the development of children's writing, emphasised the correct representation of text above children's personal expression of their ideas. In Kenya, younger children's writing consisted largely of copying. In South Africa too, it has been noted that despite the success and power of the methodology, and despite ample guidance about expressive and communicative writing in the Breakthrough teacher's manual (Molteno Project, 2004), teachers' implementation of writing in Breakthrough classrooms is quite limited. For example, findings from ethnographic-style research (Gains, 2010) in one classroom identified that children did very little writing apart from sentence drills that copy the structure of the key sentence with the substitution of a noun.

$$
\begin{array}{ll}
\text { Example: } & \text { Mother is cooking (Key sentence) } \\
\text { Learner's 'original' sentences: } & \begin{array}{l}
\text { Brother is cooking; father is cook- } \\
\text { ing; sister is cooking etc }
\end{array}
\end{array}
$$

Following discussions about the similarities in the Kenyan and SA situations an agreement was reached to conduct a parallel research study, focusing together with teachers and teacher trainers on their own practice as writers, and to explore the hypothesis that teachers, and teacher trainers, generally do not encourage expressive and creative writing because they themselves do not routinely engage in, or with, such writing activities. This perception is supported by Calkins (1986) who argued that writing has not been a skill that was taught but rather a task that was assigned and marked by teachers. Learners were not assisted to understand the processes involved in developing a written script but emphasis was on the final product. "I do not think a single teacher ever watched me as I wrote, heard my ideas about good writing, or spoke with me about my composing strategies" (Calkins, 1986: 13). We wanted to give teacher trainers and teachers the opportunity to engage in personal expressive and creative writing and to reflect upon the process as well as on the resulting texts. There was an underlying expectation, and one that we planned to document, that the intervention might result in improved classroom practices with regard to children's expressive and creative writing.

We envisaged that the benefits accruing from the implementation of a dual-site collaborative study would include support for each other during the process of carrying out the research and the analysis of the outcomes. The focus of 
the two organisations is largely on implementation, rather than research. As a result, the tendency of school-based interventions has been to seek measurable outcomes rather than to learn from observed practice. However, this intervention, with its clear research focus, has highlighted the importance for the organisations of reflection and learning which will enrich and inform future practice. We describe, below, the development of the research in our respective countries and the results to date, before reflecting upon what has been learnt in relation to the research hypothesis and underlying expectations.

\section{Kenya}

In Kenya, financial and time constraints were particularly relevant. As a mother tongue education (MTE) specialist assigned to the Kenyan NGO, Bible Translation and Literacy, I have the role of helping to facilitate the introduction and implementation of MTE in particular language communities. ${ }^{3}$ Each MTE programme plans its activities one year in advance based on available funding, among other criteria. Funding agencies are particularly keen to see that the activities MTE programmes engage in are in accordance with those stated in their plans. I hoped to involve persons from the following groups in the research process: local education officers, MTE teacher trainers, and teachers at schools that programme staff judged to be supportive of MTE. However, since the research study was not within planned programme activities, costs needed to come from personal resources. The budget and timing therefore needed to be carefully managed.

\section{Research Plans}

I planned to travel to the research area on three occasions, each time for a period of one week, to conduct the study while also doing other Programme related work:

1. November 2009 - Explain the intervention and seek permission for the research from education officials, the language project staff and the staff at the school.

I requested three sessions during each week lasting about two hours each. I reasoned that three sessions would allow time for participants to write longer pieces and to reflect on and develop what had been written. I had verbal agreement from all groups, with a proviso by the education officers that the timing needed to be flexible.

${ }^{3}$ This paper has been collaboratively written. In the sections about Kenya, the author, often denoted by ' I' is the SIL researcher; in the section on South Africa, the author is the MILL researcher. 
2. January 2010 - Conduct the intervention with education officers and project staff who are involved in training teachers for the implementation of Mother Tongue Education in lower primary classes.

By the time of the second visit the education officers and MTE staff were unable to commit to the time and the intervention was reduced to a one-hour session. Participants were asked to write briefly about different topics; to reflect upon the process of writing, the languages they used, and the place of expressive and creative writing in lower primary classes. This session became primarily a way of introducing education officers and MTE staff to what I hoped to do with the teachers.

3. February 2010 - Conduct the intervention with teachers.

The intervention with teachers was more successful in that they agreed to meet over three days (Monday, Tuesday and Wednesday) for one and a half hours during their lunch break. They requested that lunch be provided so that they would not need to return home for lunch.

\section{The intervention with teachers}

\section{Workshop One}

All the staff except for the head teacher took part in the sessions. The teachers comprised three from pre-school or Early Childhood Development (ECD) classes, two lower primary teachers and four from upper classes. On the first day, after I explained a little more about the writing project, teachers were given exercise books and pens and asked to write on a particular topic. After about two minutes of writing they were asked to stop and to write about a different topic. About five to six topics were covered mainly dealing with their personal experiences or opinions, such as "a memorable experience during teenage years", " a place I like to be" and "one person I admire". At various points they were asked to discuss in small groups, or in the larger group, different aspects of their writing, such as their choice of language and their reactions to the process of writing.

Most wrote in English to begin with, though one ECD teacher who had received MTE training which included the orthography of the Pokomo language, Kipfokomo, wrote in Kipfokomo. The others were not confident enough in their knowledge of the orthography of Kipfokomo to commit it to paper. As the session went on most were persuaded to try to write in Kipfokomo without 
worrying too much about correct spelling, since at this time the focus was their ideas rather than the presentation. One teacher, a non-native Pokomo speaker, continued to write in English and another wrote in Kiswahili. One teacher commented on the short time given initially for writing ideas, suggesting that this enabled her to make good use of the time without thinking too much about what she was going to write. After a while teachers were asked to share their writing with each other in small groups, either by reading or by talking about what they had written. They were then asked to choose one of their pieces to develop into a longer piece of writing for publication. The first session ended as the teachers began to work on their longer pieces.

\section{Workshop Two}

I had intended that teachers would use part of the following session to develop their writing but many came to the session having already completed their writing. They had found time in their day to continue writing. One explained how he had returned to the workshop venue after he had completed the school day to improve on his writing. Another had had to visit the doctor but took her book along so that she could continue writing as she waited. Most of the session was therefore focused on editing and involving others in the drafting and editing process. Teachers read each other's writing, and input on Kipfokomo orthography was given by a member of the Pokomo MTE programme staff.

Teachers were asked their opinion about how far children could be expected to engage in a similar writing activity. General agreement was expressed that the focused writing activities could also be done with children. However, when asked if they would be prepared to try the activity with their classes and report back to the group the following day, only two teachers from the upper classes volunteered immediately. After some persuasion a standard two teacher and an ECD teacher also agreed to try the process with their classes. Exercise books had been bought for each child in the school to encourage the exploration of expressive and creative writing. These books were to be used by the children and brought back to the group the following day. In the meantime I typed and printed the teachers' writing for final editing the following day.

\section{Workshop Three}

On day three the teachers who had volunteered returned with the children's books. They shared what they had asked the children to do and showed the results. The ECD children had drawn pictures of their families and labelled each picture. The teacher said she had spent two hours on the activity and the children had copied the writing from the blackboard. The standard three 
teacher said she had elicited many ideas verbally from the children before asking them to choose one topic to write about. The class spent about an hour on the activity and most wrote nearly a page. Children from class seven and eight wrote longer pieces, mostly in Swahili but a few were written in Kipfokomo.

When I asked one teacher from the upper school why he had volunteered to do the writing with his class, he said he wanted to learn about any weaknesses in his teaching and to be open with the other teachers. When I asked others why they did not immediately volunteer, the general feeling was that children from the upper primary were already able to form letters and sentences correctly so could concentrate on the creative element. Copying was thought to be the best way to get younger children to write. During this session teachers were given time to discuss among themselves if, and how, the strategies they had experienced over the three days could be incorporated in their teaching. I was later told that there was a divide between mainly upper primary teachers, who felt that incorporating the strategies in the school would be possible and beneficial, and who suggested ways in which this could be done, and teachers of the younger children, who felt that there was no need to include creative writing in normal school practice.

The teachers' writing from Workshop Two was further edited by teachers, again drawing on collaboration in the process. These versions were later published in book form, after being finally edited by a member of the Pokomo MTE staff. Three copies of an eleven page A4 book entitled "Hewani Teachers Write Their Thoughts and Stories" were placed in the staffroom the following day. I was interested to observe teachers' reactions as they saw this simple book - a stapled-together printout of their writing. The books attracted immediate attention as teachers entered the room, took copies and began reading. The head teacher was seen later sitting in the playground reading a copy.

\section{Reflection}

The intervention was very short due to time and funding constraints. Perhaps the period was too brief for notable impacts to be expected on teachers' practice. However over the three days of the intervention and the two days that followed, when I was able to spend two full days in the school, there were some positive indications that the intervention had the potential to positively impact teachers' practice of developing children's expressive and creative writing:

- The teachers were keen to write.

- They were very willing to write in their mother tongue, Kipfokomo. 
- Working with all the teachers in one school facilitated mutual understanding and reflection which could potentially provide support for teachers wanting to attempt the suggested innovation.

- Discussion revealed teachers' ideas about what constitutes writing at the early stages and what learners at this stage are capable of and allowed other views to be expressed.

- The goal of eventual publication provided a purpose for writing and for illustrating the stages in the process towards the final copy such as drafting ideas, writing, crafting and editing.

- A few teachers were willing to attempt the new ideas in their classes and share their experience with their colleagues.

A further positive outcome was seen in the days following the intervention. I was asked by one of the teachers of the upper class to implement the writing workshop activities with the children. At the end of the period, during which many children wrote in their mother tongue, the teacher announced that every Friday he would be doing creative writing with his class, affording the opportunity for expression in any language. The students' initial reservations about writing in Kipfokomo, based on concerns about accuracy in spelling, ${ }^{4}$ were overcome by persuasion, and one child was observed to write with a great deal more fluency when writing in Kipfokomo than in English. Another commented that writing in Kipfokomo was not as difficult as she had thought but that she would still like to know how to write the language properly.

Despite these positive indications, one ECD teacher said she had spent two hours getting children to copy pictures of their family and label the pictures. This shows that greater understanding is needed of the purpose and value of expressive writing, particularly with early learners. I was not invited to implement writing activities with the lower primary classes, but it is probable that the teachers of these classes will need more exposure to and experience of expressive writing before being persuaded of its value for their classes. It would be useful for them to observe young children writing and reading back their ideas, and to gain an appreciation of what 'mistakes' reveal about what and how children are learning. Such experiences, gained over time, might encourage them to value children's reflective and creative writing, and to add it to copying as part of children's writing repertoire.

\footnotetext{
${ }^{4}$ There are also diacritic marks in written Kipfokomo.
} 


\section{Challenges and possibilities}

One key challenge is located in teachers' perceptions. Most lower primary teachers do not see a role for creative writing with their children. Action research where teachers are supported to implement and reflect on changed writing pedagogy may be the right way to help teachers to engage reflectively with education innovation and to explore its impact on children's confidence and competence as meaning-makers.

However, even with a great deal of experience there is never a guarantee that teachers will include innovations in their practice. A number of studies have noted that even after extensive interaction involving policy statements, teaching and learning materials and special training, there is often little long-term change in teachers' practice (Janks, 2010; Williams, 2007). Teachers tend to adhere to an interpretation of the curriculum that has characterised their usual practice and that of their colleagues. In this school, teachers of the younger children did not appear to be able to envisage the benefits of children writing independently, when it was likely that this would be done less than perfectly. They were, therefore, not inclined to find ways of incorporating independent writing activities into their practice. Instead, copying from the blackboard was thought to be the best way of helping children to develop writing. Implicit in this notion is that children are prevented from expressing themselves in the written form until such time as they have mastered the technicalities of letter formation and spelling rules. A process of development which includes making and learning from mistakes, as children became conversant with writing conventions, was not part of their understanding. Small incremental changes over time, though not easily achieved, may be all that can reasonably be aimed for.

Another challenge relates to the acceptability to teachers of the source of suggested educational innovation. In Kenya, curriculum is formulated by the Kenya Institute of Education (KIE). The Mother Tongue section of the Primary Education Syllabus covers Standards One to Three, the levels in which the Mother Tongue subject is included. The listed objectives, learning experiences and assessment activities for 'Writing' in the Mother Tongue seem to emphasise the correct formation of letters, words and sentences, with indications that this is achieved by copying. However, also included in the objectives are the following statements for Standards One and Two, "Use pictures, symbols, or isolated letters, words and phrases to communicate meaning" and "Produce simple guided pieces of writing" and, for Standard Three, "Write own stories based on familiar experiences" (KIE 2002). These latter objectives do relate to expressive writing in the early stages of primary schooling, and yet this type of writing is not routinely seen in classrooms. Clarification on this disjuncture is offered by sociologists who have shown that regular interactions, which 
include particular ways of doing things, reinforce beliefs about the course of action that is deemed to be correct, and have a greater influence than written stipulations (Giddens, 1984; Wells, 2007). For teachers, what constitutes young children's writing is therefore likely to be based much more on usual practice than on written objectives or suggestions from one-off innovations.

A series of small whole-school action research projects may provide the opportunity for teachers not only to experience and reflect on innovative strategies but also provide reinforcement for the new strategies to be viewed as acceptable courses of action - in effect, building a community of practice (Wright, 2007) around this aspect of literacy. In the long term, a focus on expressive and creative writing might also help to develop competent and confident writers in the mother tongue, which are sorely needed if wide availability of mother tongue literature is to become a reality.

\section{South Africa}

\section{The proposed intervention}

There were to be three workshops spaced about two months apart. The participation of teachers was to be voluntary and the intervention would focus on increasing teachers' own experience and understanding of creative and expressive writing. As mentioned above, the underlying expectation was that after the three workshops it might be possible to record increased teacher confidence and competence with regard to expressive writing and that this in turn might have an impact on, and improvement of writing pedagogy. The workshops were scheduled to take place for two hours after school.

\section{Setting up}

In order to select the participating schools, in November 2009 contact was made with District officials of two District offices serving urban and periurban schools. A desirable, although not essential criterion for selection was that the schools would be teaching Home Language using Breakthrough to Literacy. This would mean, hopefully, that teachers, having been trained by MILL, would have competence in the teaching of mother tongue and it would also mean that any positive impact of the intervention would enhance teachers' competence as Breakthrough teachers, and hence have a positive impact also on their learners. 
The curriculum advisors in both district offices were enthusiastic about the idea of the project but protocol required that an intervention of this kind be approved in writing at provincial level. There was therefore a necessary delay in which protocol was duly addressed by way of the completion of a research request form. The application gained provincial approval but it then required that a memorandum of understanding be drawn up and signed between MILL, as service provider, and the Districts concerned.

The process of ensuring compliance with provincial and District protocol meant that the first workshop in the school in District A did not take place until late February, with others planned for May and September. Meetings in District $B$ about the intervention were delayed pending the receipt of approval from the relevant District official. This delay resulted in the meeting taking place in February and workshops commencing from April onwards. What follows is a report on the series of workshops implemented in the same school in District A.

\section{The process}

\section{Workshop One}

In District A, the first workshop took place with twenty-nine teachers. It seemed that they were initially bemused because the approach of this workshop, instead of offering training in classroom materials or methodology as usual, focused on them as individuals, requiring them to express themselves through various writing exercises and activities.

The workshop icebreaker involved designing a tee-shirt with logos on it; this afforded a fun and supposedly non-threatening context for teachers to provide information about themselves, their objectives for the workshop and to reflect on their current writing and reading practices. It was also an exercise that teachers could use with their own learners, showing that writing takes different forms and need not only be narrative or expository text.

We then talked about and generated a list of the writing activities that the teachers engage in, in every-day life. Moving into the practice of writing, teachers were given a blank, unlined sheet of paper and asked to write three things that they feel when faced with a blank sheet of paper and being asked to write. In other words, the workshop was recognising and acknowledging the range of emotional responses involved in writing. Implicit in this recognition is that the learners likewise may have similar 'performance-related' concerns that need to be acknowledged and addressed. 
Free writing (Elbow, 1973), the process by which one simply writes for a given time period without judgement and without editing or correcting oneself, is an excellent strategy for addressing 'writer's block'. Thus, after a brief explanation of the purpose of the process, teachers were asked to free-write about how they feel when faced with a blank page and being asked to write.

Calkins (1986) provides a reflection of how he felt as he stared at a piece of paper before writing. He says he felt hollow and anxious, and would procrastinate before actually attempting to write. These feelings and behavioural tendencies were a result of feeling incompetent, as there was no clear and productive guide on the processes involved in writing. Writing therefore felt more like a chore than an experience that could be enjoyed. Such experiences are important to note, as they provide a reference point for the limitations that teachers may have when required to teach writing, as they themselves almost certainly did not have positive experiences of writing pedagogy as learners or as student teachers.

It was interesting that whilst about a third of the teachers became readily involved and wrote freely and with enthusiasm, others seemed to continue to be blocked; a few did not even write at all. At the end of the activity, I asked the teachers how they felt about this exercise; whether it had freed them from the usual blockages that most of us feel when we are asked to write. It was interesting to note that none of the teachers responded by reflecting on how the exercise had made them feel; they responded rather by reading out what they had written. Whilst this mismatch may suggest that I had not posed the question clearly enough, it may also indicate that reflection on own practice may not be easily or readily done.

The closing session aimed to generate reflection about how the workshop activities could be used with learners, and to seek agreement that at least one activity would be implemented with their learners before the next workshop.

\section{Workshop 2}

It had become clear that the original schedule, with several weeks' gap between workshops, was problematic because of the need for continuity and sustained momentum. Therefore, the second workshop took place a month earlier than planned, at which nineteen teachers were present. Several teachers arrived late, and clearly many of them, after a day's teaching, showed signs of fatigue. Even though the workshop was scheduled for $1.30 \mathrm{pm}$ to $3.30 \mathrm{pm}$, it actually started at $1.35 \mathrm{pm}$, with teachers arriving at different times. However, those who did arrive on time were asked to read a letter 'puzzle' that involved pictograms 
for words. Although this icebreaker activity was enjoyable, it was noted by one teacher that the idea would not translate well into the language that she teaches, isiXhosa, because it was based on the concept of homonyms, of which there are very few in most of the African languages of South Africa.

Early in the workshop, during the recap of the previous session, it emerged that none of the teachers had implemented any of the ideas introduced in that session. This is possibly related to the fact that there had been a two-month gap since the first workshop and that the lack of follow-up had resulted in teachers losing motivation or focus. Therefore, the point was strongly reiterated that although these workshops address teachers' own writing skills, there is an additional objective for them to reflect on how they could implement the workshop activities with their learners.

Teachers were asked to free-write about their very earliest experiences and memories of developing an understanding of the concept and practice of writing; in other words, to recall their earliest memories of 'doing writing. As in the previous workshop, during the feedback session, in addition to sharing what had been written, reflective feedback was sought on the experience of free writing, as to whether it frees up creativity, as it is supposed to, or not. Again, teachers were not able to, or did not give this kind of reflective feedback, focusing rather on retelling what they had written.

The next session focused on deepening teachers' awareness of style in narrative text. Two versions of an introductory chapter of a children's story were presented for evaluation and comparison. One was a plain précised version of an extract from an expressive text by the South African writer, Chris Van Wyk (2006). The plain version was shown first (although for the purposes of the exercise, they were not told that this was a précis) and discussed. Then the original text was shown for comparison and analysis of the textual strategies used by the writer to communicate more effectively and expressively with the reader. Drawing on the readings and the discussion, teachers were asked to write about an item that has special meaning for them. There was no time left for peer review and editing, so the completed texts were taken away and typed up for the next session, at which teachers would learn about and practise process writing - drafting, reflecting, redrafting, editing and then publishing a final version.

At the end of the session it was agreed that the workshops needed to occur more frequently to maintain the momentum. The need was stressed for teachers to do 'homework' before the next workshop. They were asked to do one piece of free writing on anything that they wished, and also to use one idea from this workshop with their learners. Teachers were also asked to bring 
samples of their learners' writing to the next workshop, so the impact, if any, of the workshop on the learners' writing could be identified. It is hoped that there will continue to be involvement with these teachers until the end of October of the academic year, thus affording a sufficient amount of time over which to observe change and/or improvement.

\section{Workshop Three}

Twenty-one teachers attended the workshop and, since it again started late, only one hour was available for the activities. Unlike in the Kenyan experience, the teachers did not do any writing between the workshops. Although their enthusiasm for these workshops seemed to be increasing, at the start of each workshop, inhibitions about writing had to be overcome anew. The first activity in each workshop was therefore an ice-breaker, which on this occasion was a group writing activity. Teachers wrote one sentence on a page and passed it to their neighbour for the next sentence to be written. They were encouraged to write in any chosen language. Some wrote in English, others in isiXhosa, isiZulu, Tshivenda or Sepedi (five of the eleven official languages of South Africa). This exercise did indeed break the ice, affording cognisance of the value of multilingualism and the multi-lingual nature of the school. It also provided an opportunity to enjoy a collaborative and non-threatening experience of expressive writing.

The main activity intended for the third workshop was to peer-edit and redraft the pieces started in the previous workshop. Drafting, editing, redrafting and publishing of written work are requirements of the languages curriculum (DoE, 2002); but due to the fact that teachers have not been exposed to this practice, there is very little evidence that it is done with learners. Drafting, editing, redrafting and publishing, regarded as features of the Writing Process (Emig, 1971), are based on the assumption that learners need to engage in these processes in order to understand writing as a meaningful generative activity in which ideas can be communicated to different audiences. Auerbach (1999) argues that while the process approach focuses on meaning, the formal features of orthography and writing are not ignored. Supporters of the process approach argue that increasing accuracy and enhanced expression evolve through drafting, revision, and editing. Auerbach (1999) further asserts that this approach to writing values learners' lives and voices, creating a pathway for better language acquisition as well as self-discovery. The importance of including these activities in this writing workshop series is thus fundamental to this project. 
Criteria for feedback and a role-play exercise for giving feedback were provided by the two facilitators. As the teachers engaged in the process, it became clear that more time was required than was available for the activity, because of the teachers' lack of familiarity with the experience of giving and receiving feedback on their writing. There is, thus, a need for more time to be devoted for teachers to gain experience and confidence in editing and redrafting. It was also apparent that teachers struggled to distinguish between the developmental stages of the writing process and the more familiar act of marking.

\section{Reflections on the South African study}

Although three workshops were planned for this study, it became apparent that the development of primary school teachers' understanding and practice around expressive writing requires more than three short workshops. It is hoped that further workshops will be possible for and welcomed by these teachers. However, although it will be necessary to implement further workshops to be able to report with regard to changed practice, even at this mid-point in the study, the first part of the hypothesis has been corroborated; teachers, in this school at least, have little experience of creative and/or expressive writing, and this does relate to the implementation of a limited writing pedagogy that prioritises form over content.

It is heartening that there appears to be a sustained interest in the content and practices of these workshops, despite the somewhat sporadic attendance and late arrival of teachers. The difficulties with regard to eliciting reflective feedback from the teachers is of interest, although it would not be fair to draw conclusions about this at so early a stage in the process. It would be worth exploring further whether it relates to lack of confidence, or cautiousness around a new discourse, or it could reveal that reflective practice is for these teachers, a challenging cognitive activity.

The problem of continuity related to the two-month gap between the first and second workshops indicates the importance of maintaining momentum with this type of intervention. Even when the workshops are spaced more closely together, one and a half hours is very little time within which to address the lack of experience of expressive writing and writing pedagogy. Unlike in the Kenyan section of this study, teachers in this school did not do any writing between the workshops, even though the value of practising the skills with learners and doing individual homework had been emphasised. 


\section{Reflection on the process of parallel research}

This parallel research project was rooted in collaboration. It was out of the desire to explore the possibilities of collaboration between SIL (Kenya) and MILL (South Africa) that joint observation of children's writing occurred. This led to the shared realisation that, in both countries, teachers' approaches to developing children's writing were failing to take account of their capacity for creativity and/or expression.

One of the strengths of parallel research was that it was not necessary for the research design to be exactly replicated in each setting. Rather, each researcher could take account of the situations prevailing in each country to formulate an appropriate design. At the same time, the sharing of developing designs, and the process of the research enabled each researcher to learn from the other and to reflect upon their own responses in the light of the other's analysis.

Action research projects conducted in parallel settings enable researchers to learn from the process both within their own and in other settings. Further, where financial constraints preclude large-scale research, small-scale action research studies undertaken by different researchers provide a cost-effective means of using available resources to gain knowledge arising from diverse situations. Finally, parallel research is a valuable way in which organisations working towards similar ends can collaborate in the achievement of those ends. For both the researchers involved in this project the experience of parallel research has been motivating and interesting.

\section{Key findings and recommendations}

Both researchers are careful to acknowledge that the short time of the intervention precludes the declaration of conclusive statements about its impact. Nonetheless, there were clear findings which have emerged in both sites. The non-threatening activities in the workshops encouraged teachers to write, though it appears that more engagement with reflective and creative writing, (their own and others') may be needed before the impact is seen in teachers' discussions of their writing and in their facilitation of children's writing. The work undertaken thus far suggests that there are limitations in teachers' knowledge, skills and confidence with regard to writing and writing pedagogy. The activities reported in this article sought to address these limitations and provide teachers with increased confidence and strategies that they could use in teaching writing with their learners. 
In-service primary school interventions aimed at improving literacy teaching often focus more on the teaching of reading than on developing learners' writing skills. This is highly problematic, given that students later in their school lives will be judged almost entirely on their ability to write effectively and meaningfully. This study highlights the need for in-service and pre-service teacher education to place emphasis on writing pedagogy, and that such work needs to take place over an extended period of time in order for sustainable change to be effected.

Action research is a valuable means of analysing and improving practice. We believe that collaborative action research that explores and extends teachers' writing skills and confidence, combined with deliberate approaches to extending and improving writing pedagogy has the potential to make a difference to teachers' approach to writing pedagogy in Africa. Only when teachers themselves have experienced the potential for writing pedagogy to give children "some space for decision-making" (Dyson, 2001:1) and to reveal their "powers of adaptation and improvisation" (Dyson, 2001:1) are we likely to see changes in learners' exercise books in South African and Kenyan primary schools.

It is the hope of these researchers that we will then find texts that go beyond the scope of neat lines of copied text, and be invited into the written worlds of learners' unbounded imaginations.

\section{References}

Auerbach, E. 1999. The power of writing, the writing of power: Approaches to adult ESOL writing instruction. Focus on Basics: Connecting Research and Practice, 3D. Available url: http://www.ncsall.net/?id=341

Calkins, L. M. 1986. The art of teaching writing. Portsmouth, NH: Heinemann.

Department of Education. 2002. Revised National Curriculum Statement Grades R-9 (Schools) Policy, Languages: English Home Language. Pretoria: Department of Education.

Dyson, A. H. 2001. Where are the childhoods in childhood literacy? An exploration in outer (school) space. Journal of Early Childhood Literacy, 1(1): 9-39.

Elbow, P. 1973. Writing without teachers. New York: Oxford University Press.

Emig, J. 1971. The Composing Processes of Twelfth Graders. Urbana: NCTE.

Gains, P. 2010. Learning About Literacy: Teachers' conceptualisations and enactments of early literacy pedagogy in South African Grade One classrooms. Unpublished doctoral thesis, University of the Witwatersrand.

Giddens, A. 1984. The Constitution of Society. Cambridge: Polity Press.

Halliday, M. A. K. 1978. Language as Social Semiotic. London: Edward Arnold.

Janks, H. 2010. Literacy and Power. London: Routledge.

Kenya Institute of Education. 2002. Primary Education Syllabus Volume 1. Nairobi: KIE.

Molteno Project. 2004. Breakthrough to Literacy: Teacher's Guide. Cape Town: Maskew Miller Longman. 
Van Wyk, C. 2006. Ouma Ruby's Secret. Johannesburg: Giraffe Books.

Wells, G. 2007. Who we become depends on the company we keep and on what we do and say together. International Journal of Educational Research, 46(1-2): 100-103.

Williams, E. 2007. Extensive reading in Malawi: Inadequate implementation or inappropriate innovation? Journal of Research in Reading, 30(1): 59-79.

Wright, N. 2007. Building literacy communities of practice across subject disciplines in secondary schools. Language and Education, 21(5): 420-33. 


\title{
This is Literacy! Reading of photographs in research on San students' literacy in a Remote Dweller School in Botswana
}

\author{
AFFILIATION Communication and Study Skills Unit, University of Botswana \\ LONE E. KETSITLILE Communication and Study Skills Unit, University of \\ Botswana
}

Introduction

I discuss here part of my larger study which investigated what San students and their non-San friends in a Remote Area Dweller (RAD) Junior Secondary School in Botswana understand as literacy in school and at home. A narrative case study approach was used to gain an in-depth understanding of what students' value and understand by literacy. Findings across participants' stories revealed that they saw literacy as those things that had value to them and these influenced how they read 'the word' and 'the world'. Storytelling, games, singing, knowledge of different plants, basket weaving and sculpting were variously identified as literacy by the six San and Tswana participants.

\section{Purpose of the study}

The purpose of this discussion paper is to enquire about the following question: What do San children value and find meaningful in their home and school environments? How does this relate to the possibilities for literacy learning? This work is taken from my PhD study (Ketsitile, 2009). This larger study examines the struggles of San children in a difficult schooling environment where they battle with speaking, reading and writing challenges, in English particularly, as well as the disparaging views of San children held by many of the teachers in the school. The students struggle to find points of connection and interest with school work that bears no relation to their out-ofschool knowledge and family practices. Gonzalez, Moll and Amanti (2001) talk of funds of knowledge as literacy that children bring to schools. They encourage teachers to recognize and tap from such knowledge. Clearly, this was not being done at this Junior Secondary School and these photpgraphs start to examine what these out of school interests and knowledge might be. My $\mathrm{PhD}$ research explores these concerns from other angles as well, including the recording and discussion of the narrative resources that these children get from the stories their parents 